\title{
The patterns of accessing learning management system among students
}

\author{
Akibu Mahmoud Abdullahi, Mokhairi Makhtar, Suhailan Safie \\ Faculty of Informatics and Computing, Universiti Sultan Zainal Abidin, Terengganu, Malaysia
}

\begin{abstract}
Article Info
ABSTRACT

Article history:

Received Sep 18, 2018

Revised Nov 19, 2018

Accepted Nov 30, 2018

Learning Management System (LMS) is an online software that was hosted on a server and designed specifically to manage learners' information, course registration, learning content, and assessment tool. Educational data mining is a way of evaluating and using methods for examining the unique and large dataset that come from educational field, and applying those in order to understand how students learn and the settings in which they learn. Many students use to miss some of the activities posted by their instructors, due to

\section{Keywords:} the short deadline, and they are not accessing the LMS regularly or every day. The purpose of this paper is to explore the way on how student access

Data mining

Educational data mining

Learning management system (LMS) LMS and which day is the most frequent accessed. The findings show that, the total number of accessing LMS among 33 students is 16060, and the mean is 486.67, S16 recorded the highest number of accessing the LMS (965 access), while S24 as the least number of access (275). And the correlation between Tuesdays is significant, positive and strong correlation with Wednesdays (0.546), and positive, but weak with Thursdays (0.292), Fridays (0.244), Saturdays (0.334), and Sundays (0.291).
\end{abstract}

Copyright $\odot 2019$ Institute of Advanced Engineering and Science. All rights reserved.

\section{Corresponding Author:}

Akibu Mahmoud Abdullahi,

Faculty of Informatics and Computing,

Universiti Sultan Zainal Abidin,

Terengganu, Malaysia.

Email: akibu1989@hotmail.com

\section{INTRODUCTION}

Learning Management System, which was famously known as LMS is an online software platform that was created for the purpose of distributing of information and communication between learners, instructors, and administrators. LMS has become the most stalwart platform for managing an e-learning environment [1]. Universitiesand institutions are using LMS to prop up teaching, learning, and supplement traditional teaching (face-to-face) distribution where instructors are able to share materials through internet [2]. Learning Management System is an online software that was hosted on a server and designed specifically to manage learners' information, course registration, learning content, and assessment tool [3]. LMS also allows an interaction between student-to-student, student-to-teachers, student-to-content, teacherto-teacher, teacher-to-student, teacher-to-content, and content-to-content, content-to-student and content-toteacher [4]. LMS was particularly developed for controlling courses that are offered online, transmitting materials as well as permitting collaboration and communication between learners and instructors. LMS is a tool that offers a site to teach and learn without relying on the time zone and boundaries [5-6].

Data Mining is the clipping of information from a gargantuan massive of data. Data mining is the study of collecting, cleaning, processing, analysing and finding useful information from the data [7-8]. Data Mining is defined as a way of solving problems by analysing the data that are already displayed in datasets. And it was also defined as the way of finding out useful patterns in data [9]. Data Mining is an area of bring to light current, valid, interesting and utilitarian information from huge amount of dataset. 
Different fields are applying data mining including government, banking, cybersecurity, entertainment, finance, hospital, engineering, biomedicine, education etc. [10-11].

Data Mining methods that are applying in the field of education to discover educational data is called Educational Data Mining (EDM) which involved with establishing, researching and using data mining techniques to discover patterns in vast accumulations of educational data that would be difficult to analyse because of the immense large of data that exist in. Educational data mining was also defined as a way of evaluating and using methods for examining the unique and large dataset that come from educational field, and applying those in order to understand how students learn and the settings in which they learn [12]. Data mining methods in educational settings shows the way to new awareness on learner's interaction, communication, behaviour and learning paths, and also to rehabilitate teaching and learning [13]. EDM is the combination of three main fields: computer science, statistics and education.

Universities and colleges are struggling and sift through a way that they will use in order to attract and make their students to be more engaged, collaborated, communicated and applied their understanding. Nowadays, most of colleges and universities are transforming education from face-to-face to an online and some to blended learning, which is the merging of both face-to-face and online teaching. It was reported that in 2013 there were about 7.1 million students registered in online courses in higher education. LMS has huge amount of data related to students' record, profile, result, interaction, activities, and frequent of accessing LMS using browser [14-15].

Due to the massive amount of such data, instructors and administrators were yearning to find out a way on how to improve teaching and learning. "There were no storage techniques that enable the analytical study of the information present in the Learning Management System" (Garcia \& Secades, 2013; p. 313), but there are so many ways and methods that analysts may use to review about this data. Educational data mining is the way which will help to measure and analyse such huge data, it becomes a mirror for instructors to see through the movement of the students and their activities. But taking an action to solve the problem that was encountered is in the hand of instructors [16]. The objectives of the research are to: i). To study the patters of accessing Learning Management System. ii). To explore the best day of accessing Learning Management System. iii). And To discover the relationship between the days based on accessing Learning Management System among students.

\section{LEARNING MANAGEMENT SYSTEM (LMS) PLATFORMS}

Kasim and Khalid (2016) discussed and compared between some available platforms of LMS in their research, and categorized these platforms into two types which are; (i) open source in which the codes are free to use, (ii) commercial which the codes are not free. There are many open sources LSM platforms which are available to use for free, among these open sources are Moodle [17], Atutor [18], Sakai [19], Schoology [20] and Edmodo [21-22]. Meanwhile, the commercial LMS platforms include LitMos, Blackboard, SuccessFactors, SumTotal, Angel Learning, etc.

\section{EDUCATIONAL DATA MINING TOOLS}

Educational data mining tools can be divided into two categories, commercial and open source. Commercial Learning Analytics tools are SPSS, Tableau, NVivo, Stata, Blackboard, Many Eyes, Infochimps, etc. While Open Source educational data mining include R, Weka, SNAPP, Netlytic, etc. Some of the tools will be discussed below:

Commercial educational data mining tools are software developed by commercial companies. Examples of these softwares are:

a) Tableau: the idea of initiating Tableau began between 1999 and 2002 from Department of Computer Science in Stanford University. Tableau was founded by Chris Stolte in 2003. Tableau is an interactive data visualization software, the company is based in Washington, United State. There are five ways of accessing Tableau software: Desktop, Server, Online, Public, and Mobile [23].

b) STATA: in 1985 a graduate from University of California William Gould developed a statistical software called Stata. The software was written in C programming language, for version one, Gould spent almost one year in writing the codes of Stata [24].

c) Blackboard: is an analytical software that was developed by blackboard Learning Management System. This software will capture student data and transform it into operational information. It gives detail about learning outcomes, evaluation of tools, and pattern of usage [25].

d) SPSS: in 1975 Bent, Nie and Hull graduated students from University of Stanford developed SPSS statistical software. SPSS stand for Statistical Package for the Social Sciences. In 2009 IBM acquired SPSS. The statistics that includes in SPSS are t-test, Descriptive, Cross tabulation, ANOVA, Cluster 
Analysis, Linear Regression, Means, Nonparametric test etc.

The open source educational data mining tools are developed mainly for research and for free, they are not well developed compared to commercial software. The open EDM tools are discussed briefly below:

a) SNAPP: stand for Social Networks Adapting Pedagogical Practice, is an open source, free software that is use for data visualization and social network analysis of discussion forum activity in Learning Management System. It gives information about learners' engagement who participated in a forum discussion and interaction between them. SNAPP developed by group of researchers who participated from different universities around the world, The University of Queensland, Murdoch University, University of Wollongong, RMIT University, and University of British Columbia [25].

b) Weka: is another open source EDM tool that was developed by New Zealand's University of Waikato. It was written using Java programming language. The Weka includes tools like classification, clustering, visualization, data pre-processing, regression, etc. [9].

c) Netlytic: is a social network software that summarizes huge amount of data from learners' interaction, engagement in chat, forum discussion, twitter, Youtube etc.

\section{RESEARCH METHOD}

In this study quantitative research approach is going to be used which "evolves the collection of data so that information can be quantified and subjected to statistical treatment in order to support or refute alternate knowledge claims" (Williams, 2007; p. 66). Two research designs, descriptive and inferential statistics will be used. Descriptive statistics is used to investigate the condition, and its current situation. Inferential statistics through correlational is used to find out the relationship between two or more variables in the study [29]. In this study, the EPD212 Product Design \& Development is chosen. A total of 33 students registering in this course will be involved as the research sample. The semester has 17 weeks for each course to be completed. The course is offered both online and offline. In online, the instructor uses Moodle learning management system to upload the materials, and assignment, as well as create forums that the student will use, and participate. While in offline, the instructor delivers the lecture to the student face-to-face in the class. The students have computer skills.

The resources use, and activities are extracted from the university's e-learn. The university is using Moodle platform. The Moodle platform provided a plugins called LOGS. The Logs is plugged into the LMS for the purpose of recording the actions or movements of the students in the LMS and to store it. The Figure 1,2 and 3 show the three processes that followed when collecting the data.

The Figure 1 is the Logs plugins that allows instructor or administrator to choose which logs he wants to appear or download. In this study, the course, all participants, all days, all activities, all actions, and all events are chosen.

There are two types of levels in the all events, (i) teaching level, and (ii) participating level as shown in Figure 2. In this study, participating is chosen to download the participant/students activities. After GET THESE LOGS is clicked, types of files popped up, and excel file is chosen to store the activities and the participant logs files.

The Figure 3 is the excel file that appears, home was clicked and click save as to save the data. After the data were extracted into excel, Tableau software is used to separate the levels as shown in Figure 2 which are Time, user full name, effected user, event context, component, event name, description, origin, and IP address.

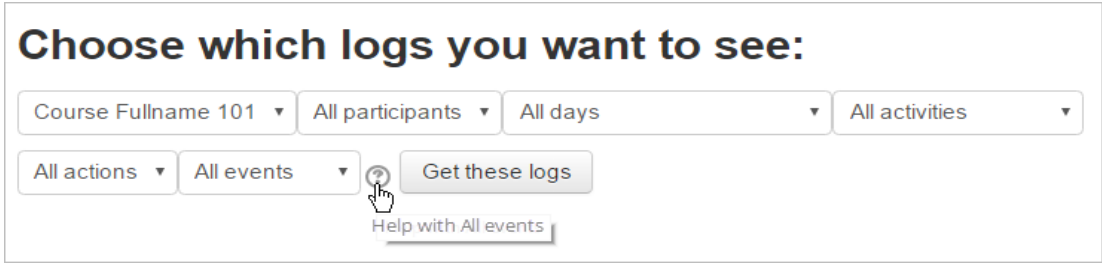

Figure 1. Moodle logs 


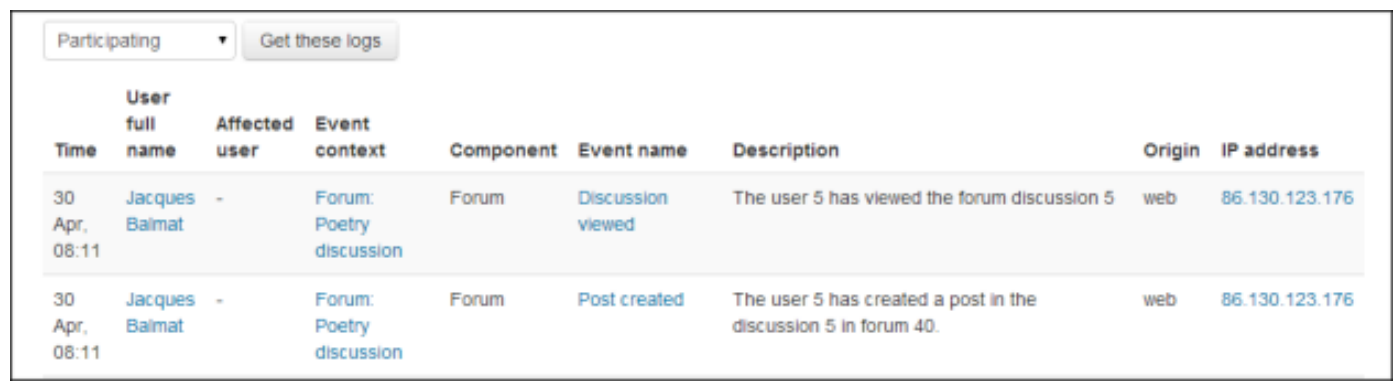

Figure 2. Moodle logs (participating)

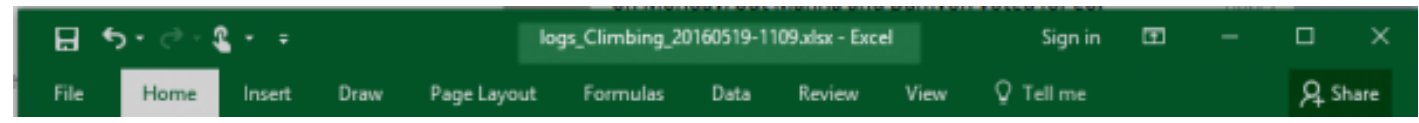

Figure 3. Microsoft excel screen

\section{RESULT AND ANALYSIS}

In this research three objectives are to be discussed, the first objectives are: To study the patters of accessing Learning Management System. The participants are 33 students from Faculty of Engineering who registered in the subject Product Design \& Development. The Students started accessing the Learning Management System on 14 February to 11 June 2017, which is around 4 months. The Educational Data Mining tool that was used for visualizing the data is Tableau. In the following Figure 4, we can visualize the most access student and the lowest as well as the average based on accessing LMS using packed bubbles. Figure 4 indicates the patterns of accessing LMS among the 33 students, the total number of accessing LMS is 16060 , and the mean is 486.67 , S16 recorded the highest number of accessing the LMS (965 access), while S24 as the least number of access (275).

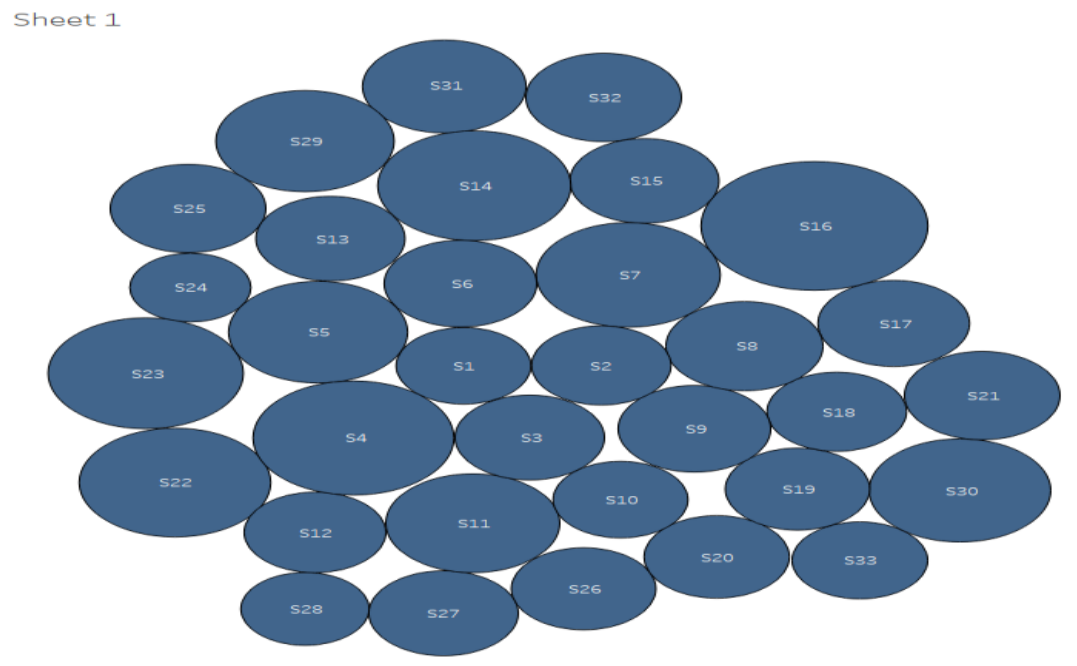

Figure 4. Patterns of accessing LMS

The second objective is to explore the best day of accessing Learning Management System. The purpose is to discover day is the most accessed day among students. We can visualize the differences in the following Figure 5 using box-and-whisker plots, while in the Table 1 the detail was displayed.

In the Table 1, Tuesday is the most frequent access by the students with 454.00, meanwhile, the mean is 306.9091, and the least of access is 227.00. The third and last objective is to discover the relationship between the days based on accessing Learning Management System among students. The following Table 2 displayed the relationship between the days. 

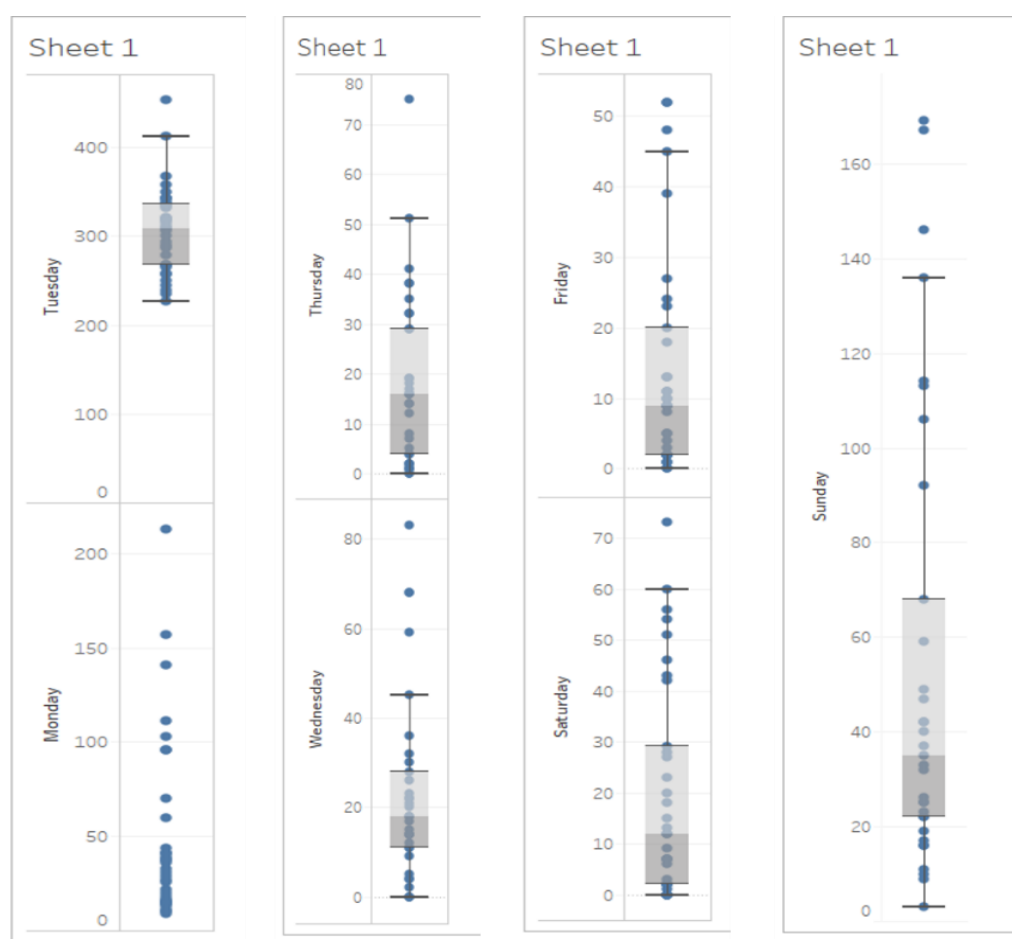

Figure 5. The most acceses days among students

Table1. The Days of Accessing LMS

\begin{tabular}{cccccc}
\hline & $\mathrm{N}$ & Minimum & Maximum & Mean & Std. Deviation \\
\hline Monday & 33 & 9.00 & 213.00 & 49.9394 & 48.58044 \\
Tuesday & 33 & 227.00 & 454.00 & 306.9091 & 50.56021 \\
Wednesday & 33 & .00 & 83.00 & 22.7576 & 20.80269 \\
Thursday & 33 & .00 & 75.00 & 18.1212 & 17.44412 \\
Friday & 33 & .00 & 52.00 & 14.5455 & 15.82935 \\
Saturday & 33 & .00 & 73.00 & 20.2424 & 21.18672 \\
Sunday & 33 & 3.00 & 169.00 & 53.6667 & 48.13047 \\
Valid N (listwise) & 33 & & & & \\
\hline
\end{tabular}

Table 2. The Correlation between the Day

\begin{tabular}{|c|c|c|c|c|c|c|c|c|}
\hline & & Monday & Tuesday & Wednesday & Thursday & Friday & Saturday & Sunday \\
\hline \multirow[t]{3}{*}{ Monday } & Pearson Correlation & 1 & $.380^{\prime \prime}$ & .274 & $.350^{x}$ & $.421^{n}$ & .240 & $.575^{111}$ \\
\hline & Sig. (2-tailed) & & .029 & .123 & .046 & .015 & .178 & .000 \\
\hline & $\mathrm{N}$ & 33 & 33 & 33 & 33 & 33 & 33 & 33 \\
\hline \multirow[t]{3}{*}{ Tuesday } & Pearson Correlation & $.380^{x}$ & 1 & $.546^{1 x}$ & .292 & .244 & .334 & .291 \\
\hline & Sig. (2-tailed) & .029 & & .001 & .100 & .172 & .057 & 101 \\
\hline & $\mathrm{N}$ & 33 & 33 & 33 & 33 & 33 & 33 & 33 \\
\hline \multirow[t]{3}{*}{ Wednesday } & Pearson Correlation & .274 & $.546^{n \pi}$ & 1 & $.432^{x}$ & .312 & .312 & .151 \\
\hline & Sig. (2-tailed) & .123 & .001 & & .012 & .077 & .077 & .400 \\
\hline & $\mathrm{N}$ & 33 & 33 & 33 & 33 & 33 & 33 & 33 \\
\hline \multirow[t]{3}{*}{ Thursday } & Pearson Correlation & $.350^{x}$ & .292 & $.432^{x}$ & 1 & $.621^{\mathrm{n}}$ & $.597^{\pi x}$ & .295 \\
\hline & Sig. (2-tailed) & .046 & .100 & .012 & & .000 & .000 & .096 \\
\hline & $N$ & 33 & 33 & 33 & 33 & 33 & 33 & 33 \\
\hline \multirow[t]{3}{*}{ Friday } & Pearson Correlation & $421^{n}$ & .244 & .312 & $.621^{\mathrm{Nx}}$ & 1 & .326 & .245 \\
\hline & Sig. (2-tailed) & .015 & .172 & .077 & .000 & & .064 & .170 \\
\hline & $\mathrm{N}$ & 33 & 33 & 33 & 33 & 33 & 33 & 33 \\
\hline \multirow[t]{3}{*}{ Saturday } & Pearson Correlation & .240 & .334 & .312 & $.597^{\mathrm{Nn}}$ & .326 & 1 & $.380^{\circ}$ \\
\hline & Sig. (2-tailed) & .178 & .057 & .077 & .000 & .064 & & .029 \\
\hline & $\mathrm{N}$ & 33 & 33 & 33 & 33 & 33 & 33 & 33 \\
\hline \multirow[t]{3}{*}{ Sunday } & Pearson Correlation & $.575^{\mathrm{kn}}$ & .291 & .151 & .295 & .245 & $.380^{\circ}$ & 1 \\
\hline & Sig. (2-tailed) & .000 & .101 & .400 & .096 & .170 & .029 & \\
\hline & $\mathrm{N}$ & 33 & 33 & 33 & 33 & 33 & 33 & 33 \\
\hline
\end{tabular}

*. Correlation is significant at the 0.05 level (2-tailed).

**. Correlation is significant at the 0.01 level (2-tailed). 
The findings show that the correlation between Mondays is significant, positive but weak correlation with Tuesdays (0.380), Wednesdays (0.274), Thursdays (0.350), Fridays (0.420), and a significant positive and strong relation with Sundays (0.575). The correlation between Tuesdays is a positive and strong correlation with Wednesdays (0.546), and positive, but weak with Thursdays (0.292), Fridays (0.244), Saturdays (0.334), and Sundays (0.291). The correlation between Wednesdays is positive and weak with Thursdays (0.4.32), Fridays and Saturdays (0.312), and Sundays (0.151). The correlation between Thursdays is positive and strong with Fridays (0.621), Saturdays (0.597), but weak with Sundays (0.295). The correlation between Fridays is significant but weak with Saturdays (0.326) and Sundays (0.245). And the between Saturdays is significant, positive with Sundays (0.380).

The purpose of this paper is to find out which day is the most and frequent accessed by the students, and we found out that Tuesdays is the most continues day of access, the 33 students were recorded that in Tuesdays they access the LMS the most compared to the remaining days. Many students use to miss some of the activities posted by their instructors, due to the deadline is may be short, and they are not accessing the LMS regularly or every day. By exploring the way student access LMS will help the instructors to find the best day to post their activities for student in order to avoid missing activities by students.

\section{CONCLUSION}

Educational Data Mining (EDM) is a clarification of gathered and produced data about learners in order to assess, evaluate their learning progress, presage and prognosticate their future performance. The purpose of EDM is to take an action after data have been collected, measured and analysed for the purpose of improvement to produce a qualitative teaching and learning. "Basically, analysis without action is not analytics, or one could even say analytics without action is just analysis". Learning analytics is not occurring only in a summative assessment stage, it is also happening in a formative assessment which instructors may use to oversee and detect the progressive performance of their learners while the course or subject is taking place. Through EDM, instructors are able to foretell and predict which student is facing academic difficulties or is on learning needs. Learning Analytics serve as a fundamental for transformation that gives a quick and new way for universities and colleges to improve their processes of teaching and learning.

\section{ACKNOWLEDGEMENT}

This work is partially supported by RMIC UniSZA (Grant R0023 CRIM/2018/03).

\section{REFERENCES}

[1] Srichanyachon, N. (2014). "EFL learners' perceptions of using LMS". Turkish Online Journal of Educational Technology, 13(4), 30-35.

[2] Sclater, N., Peasgood, A., \& Mullan, J. (2016). "Learning analytics in higher education: A review of UK and international practice Full report”, (April), 40. Retrieved from https://www.jisc.ac.uk/sites/default/files/learninganalytics-in-he-v2_0.pdf

[3] Kasim, N. N. M., \& Khalid, F. (2016). "Choosing the right learning management system (LMS) for the higher education institution context: A systematic review". International Journal of Emerging Technologies in Learning, 11(6), 55-61. https://doi.org/10.3991/ijet.v11i06.5644

[4] Adzharuddin, N. A., \& Ling, L. H. (2013). "Learning management system (LMS) among university students: Does It Work?" International Journal of E-Education, E-Business, E-Management and E-Learning, 3(3), $248-252$. https://doi.org/10.7763/IJEEEE.2013.V3.233

[5] Epignosis LLC. (2014). "e-learning Concepts, Trends, Applications. Book", 5. Retrieved from http://www.talentlms.com/elearning/elearning-101-jan2014-v1.1.pdf

[6] Sharma, A., \& Vatta, S. (2013). "Role of Learning Management Systems in Education". International Journal of Advanced Research in Computer Science and Software Engineering, 3(6), 2277-128.

[7] Aggarwal, C. C. (2015). "Data Mining: The Textbook". Springer International Publishing. https://doi.org/10.1007/978-3-319-14142-8

[8] Du, S. D. and X. (2011). "Data Mining MAchine Learning in Cybersecurity".

[9] Witten, I. H., Frank, E., \& Hall, M. a. (2011). "Data Mining: Practical Machine Learning Tools and Techniques" (Google eBook). Complementary literature None. https://doi.org/0120884070, 9780120884070

[10] Chen, C.-T., \& Chang, K.-Y. (2017). "A Study on the Rare Factors Exploration of Learning Effectiveness by Using Fuzzy Data Mining”. Eurasia Journal of Mathematics, Science and Technology Education, 13(6), 2235-2253. https://doi.org/10.12973/eurasia.2017.01223a

[11] Pereira, B. A., Pai, A., \& Fernandes, C. (2017). "A Comparative Analysis of Decision Tree Algorithms for Predicting Student's Performance", 7(4). 
[12] Vahdat, M., Ghio, A., Oneto, L., Anguita, D., Funk, M., \& Rauterberg, M. (2015). "Advances in Learning Analytics and Educational Data Mining". Proceedings of the 2015 European Symposium on Artitifal Neural Networks, Computational Intelligence and Machine Learning, (April), 22-24. https://doi.org/ISBN 978287587014-8.

[13] Kapur, B., Ahluwalia, N., \& Sathyaraj, R. (2017). "Comparative Study on Marks Prediction using Data Mining and Classification Algorithms". International Journal of Advanced, 8(3), 632-636. Retrieved from http://www.ijarcs.info/index.php/Ijarcs/article/view/3066

[14] Williams, D., \& Whiting, A. (2016). "Exploring the Relationship Between Student Engagement, Twitter, and a Learning Management System: A Study of Undergraduate Marketing Students". International Journal of Teaching \& Learning in Higher Education, 28(3), 302. Retrieved from https://ezproxy.eafit.edu.co/login?url=http://search.ebscohost.com/login.aspx?direct=true\&db=edo\&AN=12061738 $1 \&$ lang $=$ es\&site $=$ eds-live $\&$ scope $=$ site

[15] Shum, S. B., \& Ferguson, R. (2012). "Social Learning Analytics. Educational Technology \& Society", 15(3), 3-26. https://doi.org/10.1145/2330601.2330616

[16] García, O. A., \& Secades, V. A. (2013). "Big data and learning analytics: A potential way to optimize elearning technological tools". Proceedings of the International Conference E-Learning 2013, 313-317. Retrieved from http://www.scopus.com/inward/record.url?eid=2-s2.0-84886911408\&partnerID=tZOtx3y1

[17] Remes, R. (2005). "Learning Management System”. 14th Annual Conference of Doctoral Students, $207-212$. Retrieved from http://www.mff.cuni.cz/veda/konference/wds/proc/pdf05/WDS05_037_m8_Remes.pdf

[18] Jiugen, Y., Ruonan, X., \& Luyao, Y. (2011). "The Application of the Atutor Learning Content Management System in Teaching", 12, 57-60.

[19] Wei, Y. (2014). "The Application of Sakai in University of Science and Engineering". Education Journal, 3(4), 224-228. https://doi.org/10.11648/j.edu.20140304.13

[20] Fenton, W. (2010). "Schoology LMS". Retrieved from https://www.schoology.com

[21] Charoenwet, S., \& Christensen, A. (2016). "The effect of Edmodo learning network on students' perception, selfregulated learning behaviors and learning performance". IMSCI 2016 - 10th International Multi-Conference on Society, Cybernetics and Informatics, Proceedings, (Imsci), 297-300. Retrieved from https://www.scopus.com/inward/record.uri?eid=2-s2.085013629379\&partnerID=40\&md5=f1766af4775eb0d96a2faa8c5eecc673

[22] Simon, K. (2016). "Edmodo: The Facebook of Learning Platforms". Tesl-Ej, 20(1), 1-7. Retrieved from https://lopes.idm.oclc.org/login?url=http://search.ebscohost.com/login.aspx?direct=true\&db=ehh\&AN=116408995 $\&$ site $=$ eds-live $\&$ scope $=$ site

[23] Sood, A., Sinha, N., Dewjee, S., \& Zhao, W. (2013). “Tableau Tutorial”. Retrieved from http://casci.umd.edu/wpcontent/uploads/2013/12/Tableau-Tutorial.pdf

[24] Cox, N. J. (2005). “A brief history of Stata on its 20th anniversary". Stata Journal, 5(1), 2-18.

[25] Squillante, J., \& Hartey, T. (2014). "Analyzing Blackboard: Using a Learning Management System From the Student Perspective".

[26] Alves, P., Miranda, L., \& Morais, C. (2017). "The Influence of Virtual Learning Environments in Students' Performance". Universal Journal of Educational Research, 5(3), 517-527. https://doi.org/10.13189/ujer.2017.050325

[27] Nguyen, V. A. (2017). "Towards the implementation of an assessment-centred blended learning framework at the course level". International Journal of Information and Learning Technology, 34(1), 20-30. https://doi.org/10.1108/IJILT-08-2016-0031

[28] Park, Y., \& Jo, I.-H. (2016). "Using log variables in a learning management system to evaluate learning activity using the lens of activity theory". Assessment \& Evaluation in Higher Education, 2938(April), 1-17. https://doi.org/10.1080/02602938.2016.1158236

[29] Williams, C. (2007). "Research Methods". Journal of Business \& Economic Research, 5(3), 65-72. https://doi.org/10.1093/fampract/cmi221

[30] Martin, F., \& Ndoye, A. (2016). "Using Learning Analytics to Assess Student Learning in Online Courses". Journal of University Teaching \& Learning Practice, 13(133). https://doi.org/10.1177/0047239516656369. 